\title{
Características clínicas y demográficas de pacientes con cáncer de pulmón de células no pequeñas EGFR positivo
}

\author{
- Pedro Luis Ramos Guette, María Athenas Ramos Escalante, Diana Silva \\ Oncológica Oncocare (Bogotá, D.C.)
}

Introducción: el cáncer de pulmón de células pequeñas con mutación en el receptor EGFR tiene un mejor pronóstico que el EGFR negativo. El propósito de este estudio es describir las características clínicas, demográficas y de supervivencia de pacientes con EGFR positivo tratados con inhibidores de la tirosina-cinasa.

Materiales y métodos: se trata de un estudio observacional descriptivo, retrospectivo durante el período septiembre de 2009-marzo de 2016. Se realizaron análisis descriptivos usando medidas de tendencia central, ubicación y dispersión para las variables continuas, y frecuencias absolutas y relativas para las variables categóricas. Se estimó la supervivencia por el método de Kaplan-Meier.

Resultados: se identificaron 27 pacientes con una edad promedio de 64 años, 96\% ECOG 0-1. La histología más frecuente es adenocarcinoma en un $89 \%$, el $74 \%$ fueron hombres y un $27 \%$ de los pacientes presentaron metástasis cerebral. El 70\% recibió tratamiento con erlotinib. Tabaquismo en un $11 \%$. Régimen subsidiado un 52\%. La mediana de supervivencia global fue 34,6 meses y la de supervivencia libre de progresión fue de 20,6 meses.

Conclusiones: en los pacientes con cáncer de pulmón EGFR positivo, la histología más frecuente es adenocarcinoma, y tiene una buena sobrevida global y libre de progresión por su buen pronóstico, de acuerdo con lo descrito en la literatura. 